\title{
A Revised Discrepancy Method for Identifying Dyslexia
}

\author{
Donald D. Hammill ${ }^{1}$ • Elizabeth A. Allen ${ }^{1}$ (ID
}

Received: 3 February 2020 / Revised: 3 February 2020 / Accepted: 10 February 2020 / Published online: 5 March 2020

(C) The Author(s) 2020

\begin{abstract}
The issue of how to reliably identify students with developmental dyslexia in order that they may serve in research studies and receive appropriate intervention has been unresolved for decades. The primary issue is how to distinguish students who are likely to have dyslexia from the considerable number of students who are simply poor readers. The present study explores the feasibility of developing a valid method for selecting students with dyslexia to serve as subjects in research studies and to enroll in special intervention programs. After consulting 16 definitions of dyslexia, five common elements were identified, and operational criteria were developed for four of the elements. These criteria were applied to 70 school-identified students with dyslexia residing in eight states. The results were used to establish three categories of likelihood for dyslexia: very likely, likely, and not very likely. According to our revised discrepancy method, $51 \%$ of the students currently receiving services under the dyslexia label satisfied the dyslexia likelihood criteria of very likely or likely. The remaining $49 \%$ did not satisfy the dyslexia likelihood criteria (i.e., they were not very likely to have dyslexia). Most researchers would probably agree that the students identified by this revised discrepancy method do in fact have dyslexia (i.e., seriously low reading ability, average or better cognitive ability, and a standard score difference of 15 to 29 points [for likely] and 30 points or more [for very likely]).
\end{abstract}

Keywords Dyslexia $\cdot$ Dyslexia screening $\cdot$ Dyslexia identification $\cdot$ Reading failure $\cdot$ Achievement-cognitive discrepancy method

\section{A Revised Method for Identifying Dyslexia}

In this paper, we propose a revised discrepancy model based on definitional criteria for selecting a subset of very poor readers to serve as subjects in research studies or to receive special intervention services under the dyslexia label. The following sections (a) describe various methods currently used today to identify students who have dyslexia; (b) discuss the importance of creating valid criteria for identifying students who actually have dyslexia; (c) review 16 definitions of dyslexia; (d) extract the most common elements from those definitions; (e) provide operational criteria for each of those elements; (f) overview the methods used to validate the criteria; (g) review the results of applying these criteria to a sample of 70 students identified with dyslexia; and,

Elizabeth A. Allen

eallen@proedinc.com

Donald D. Hammill

dhammill@proedinc.com

1 PRO-ED, Inc., 8700 Shoal Creek Blvd, Austin, TX 78757, USA finally, (h) discuss the study's results, implications, and limitations.

\section{Current Methods for Identifying Students with Dyslexia}

In a recent article in Perspectives on Language and Literacy, Youman and Mather (2018) wrote:

Today, as of March of 2018, 42 states have dyslexiaspecific legislation, and, among the states that have passed laws, most have updated their education codes to clearly define dyslexia and provide guidelines to school districts on how to identify dyslexia and provide evidence-based interventions. (p. 37).

In addition to the states, many professional organizations (e.g., International Dyslexia Association, American Psychiatric Association) and individual researchers (e.g., Fletcher et al. 2018; Wagner 2018) have offered their own guidelines and methods for identifying dyslexia. Not surprisingly, these methods for identifying students with dyslexia often focus on different defining aspects. Chief among these 
are low reading achievement, discrepancy between reading and other cognitive abilities, unresponsiveness to special reading intervention, and the presence of intraindividual differences among cognitive processing strengths and weaknesses. For an in-depth review of each of these methods, see Fletcher et al. (2018).

All of the aforementioned identification methods use exclusionary criteria that require that the reading problem cannot be because of (a) intellectual disabilities, (b) uncorrected visual or auditory acuity, (c) other mental or neurological disorders, (d) emotional issues, (e) poor oral language ability, or (f) inadequate educational instruction. Unfortunately, most of these identification methods have problems with reliability and lack agreement with each other. For example, Waesche et al. (2011) found that applying a cognitive discrepancy method and an RTI-based method to the same sample resulted in only $31 \%$ agreement regarding which students qualified as having dyslexia. Applying the cognitive discrepancy method and lowachievement method to the same sample resulted in only $32 \%$ agreement. Further, these methods do not differentiate garden variety poor readers from students with dyslexia, a shortcoming that results in much confusion in the field regarding incidence rates and prognosis. In the next section, we review some of the benefits of developing alternative identification methods.

\section{The Value of Valid Identification Criteria}

The inability or reluctance of professionals and parents interested in specific learning disability/dyslexia to develop a set of valid criteria for selecting subjects for research studies and for qualifying individuals to receive special services has had dire consequences on the field. Without such criteria, professionals cannot differentiate between truly reading-disabled students and other types of poor readers (e.g., garden variety poor readers, struggling readers). This being the case, a large percentage of the subjects in research studies that claim to investigate aspects of dyslexia and the progress of students enrolled in intervention programs that are intended for students with dyslexia do not have dyslexia. In fact, researchers usually provide little or no evidence to show that they do.

The absence of generally agreed upon criteria for identifying dyslexia has plagued the field since its conception. This failure has resulted in the publication of questionable research in which the sample is referred to as having a specific learning disability (SLD) or dyslexia but, in reality, is composed of a considerable number of garden variety poor readers (Adelman 1989, 1992; DeLoach et al. 1981; Kirk and Chalfant 1984; Mather and Roberts 1994). Later in this paper, we show that $49 \%$ of the subjects used in our validating sample were classified as not very likely to have dyslexia, according to our revised discrepancy method.

The availability of generally agreed upon discrepancy criteria would be most helpful when selecting subjects for use in investigations of both theoretical and applied aspects of dyslexia and may also have implications for qualifying students for dyslexia intervention services in schools and clinics. The validity of all such research studies ultimately depends on the assumption that the individuals in the study who are labeled with "dyslexia" do, in fact, have dyslexia (Flanagan et al. 2010; Flanagan et al. 2006; Harrison and Holmes 2012; Kavale et al. 2009; Swanson 1991). This being the case, a set of valid identification criteria would allow researchers to replicate the findings of other researchers, a useful scientific activity. Using such criteria, researchers could confidently identify the incidence of dyslexia in the population, the causes of dyslexia, the correlates of dyslexia, and useful methods for teaching reading to students with dyslexia. The potential value of having valid criteria for identifying students who do in fact have dyslexia and thereby need special services and attention is obvious. While we agree that the traditional discrepancy method has its shortcomings, we believe that it can be revised into a valid method of identification on the basis of definitional criteria and specific cut scores. Further discussion of how we propose to revise the traditional discrepancy criteria to select students for special services is dealt with later in "Procedures" section of this paper.

\section{Definitions of Dyslexia}

The effort to develop a set of definition-based discrepancy criteria that can be used to identify students with dyslexia logically begins by studying existent definitions of dyslexia in order to determine those elements of agreement across definitions. Once identified, these elements can be converted into operational criteria and validated empirically.

The definitions that were studied were taken from two popular dictionaries, three psychological dictionaries, two diagnostic manuals, a medical dictionary, two linguistic dictionaries, a special education and rehabilitation dictionary, a developmental disabilities dictionary, two professional organizations, and two notable persons in the field of dyslexia. A few of these definitions are old but still relevant, while the others are drawn from current editions of dictionaries and diagnostic manuals. The basic agreement among the definitions is noteworthy. These 16 definitions are presented in the Appendix of this paper. Readers who are not familiar with the field of dyslexia will find it useful to review the definitions at this point.

\section{Five Common Elements Among Dyslexia Definitions}

The 16 definitions agreed on five elements (i.e., the elements were mentioned specifically in over $50 \%$ of the definitions). The five elements are incorporated in the following sentence: 
"Dyslexia is a serious condition (94\%) affecting the written language comprehension of words (in isolation or in context) $(100 \%)$ that is unexpected when contrasted with oral language, reasoning, or achievement ability (other than written language, of course) (56\%), and is believed to be the result of neurological and genetic factors $(50 \%)$." We briefly discuss each of the elements in this section:

\section{Dyslexia Is a Serious Problem}

Fifteen of the definitions describe dyslexia as a "severe impairment," "failure," "disability," and "disorder." These terms suggest that dyslexia is a debilitating condition that is uncommon in occurrence but is not necessarily rare.

\section{Dyslexia Is a Disorder of Written Language}

All the definitions describe dyslexia as a disorder of written language (i.e., a specific disorder affecting reading, writing, and spelling) or a "specific reading disorder."

\section{Dyslexia Is a Disorder of Word-Level Comprehension}

Three of the definitions mention "comprehension" by name, four mention the word "understand," two described the condition as "word blindness," nine simply refer to "reading," and seven specifically mention "words." We grouped all these definitions under word-level comprehension (both in isolation and context). Support for the idea that comprehension is a critical aspect of reading is found in the Reading First Impact Study Final Report (Gamse et al. 2008). This study investigated the impact of Reading First, a federal initiative designed to help all children read at or above grade level by the end of third grade. The authors selected reading comprehension as the central reading achievement construct for the study and noted that "the selection of reading comprehension reflected its importance as the 'essence of reading' that sets the stage for children's later academic success (National Institute of Child Health and Human Development 2000)" (Gamse et al. 2008, p. 10). Further support for comprehension as a critical aspect of reading can be found in a listing of 14 well-known definitions for reading (see Reid et al. 2018), all of which emphasize the essential role of meaning (i.e., comprehension) in reading. The definitions include those of Huey (1908, p. 6), Gray (1940, p. 6), Flesch (1955, p. 3), Goodman (1981, p. 477), and Kamhi and Catts (1989, p. 4).

Evidence that impaired comprehension is the critical problem in the reading of students with dyslexia does not rest solely on the definitions. Results of every meta-analysis that has studied the correlates of reading have agreed that oral or silent measures of reading comprehension, identification of real words (either in isolation or in context), spelling, and writing conventions (i.e., orthographic rules) are the best predictors of reading ability. Graphophonemic abilities involving printed letters (e.g., sound-letter relations, grapheme-sound blending) are also important predictors of reading, though they lack the diagnostic accuracy of the best predictors (Hammill and McNutt 1981; Lonigan et al. 2009; Scarborough 1998; Swanson et al. 2003).

\section{Dyslexia Is Unexpected}

Nine definitions agreed that unexpectedly low reading ability, when contrasted with other cognitive abilities (e.g., speech, intellect), cultural opportunities, or emotional factors, is a defining characteristic of dyslexia. Specifically, the reading disability is not attributable to a more general intellectual disability; external factors such as economic or environmental disadvantage, chronic abuse, or lack of education; or to acquired neurological events (e.g., stroke, brain injury); or motor, vision, or hearing disorders. This element is the basis for the use of all discrepancy models for identifying dyslexia (e.g., achievement-aptitude discrepancies among cognitive abilities).

\section{Dyslexia Is Caused by Organic Neurological and Genetic Factors}

Eight of the definitions agreed that organic neurological and genetic factors are associated with and/or cause dyslexia. This element was not operationalized because of the difficulty in setting psychometric criteria for neurological or genetic diagnostic factors. In reality, however, organicity does appear to play a role in understanding dyslexia. For example, any sample of students with dyslexia will exhibit very large differences between reading scores and cognitive scores and contain a disproportionately large number of boys. Both these observations could be interpreted as possible evidence for existence of genetic factors in individuals with dyslexia. In cases in which known readers lose their ability to read as a consequence of stroke, head injury, or similar maladies, no psychometric evidence of organicity is necessary. In such cases, we would use the term alexia rather than dyslexia.

Numerous brain neuroimaging studies have found both structural and functional differences between individuals with dyslexia and nonimpaired controls (see Deutsch et al. 2005, and Shaywitz and Shaywitz 2008, for reviews of this research). These imaging studies reveal that individuals with dyslexia have differences in brain density and structure as well as differences in brain activation during reading tasks. Because of the complexity and plasticity of the brain, researchers are unable to determine if these differences are the cause of dyslexia or a result of dyslexia. Additionally, researchers using imaging and genetic tools have been unable to identify children with dyslexia at an acceptable level of diagnostic accuracy (Eicher and Gruen 2013; Shaywitz and 
Shaywitz 2008). Nonetheless, it is clear that some individuals with dyslexia may have differences in brain structure and function. We, however, do not attempt to provide operational criteria for this element.

\section{Operational Criteria for Four of the Five Dyslexia Elements}

The definitional elements of dyslexia described in the previous section were used to develop specific identification criteria for dyslexia. These specific criteria, based on four of the definitional elements, are discussed in detail in this section.

\section{Criteria for Element 1-Dyslexia Is a Serious Problem}

Because dyslexia is a serious reading problem, students should score 84 or fewer standard score points on word reading comprehension tests (i.e., more than 1.0 standard deviations below the mean) to satisfy this element. Such low scores are indicative of "low average" or below-average ability in reading. This cut score is supported by the Diagnostic and Statistical Manual of Mental Disorders, 5th Ed. (DSM-5; American Psychiatric Association 2013), which suggests that to qualify as having dyslexia, students' reading standard scores should be at least 1.5 standard deviations or more below the mean (i.e., standard score of 78); but that, " $\ldots$ on the basis of clinical judgement, a more lenient threshold may be used (e.g., 1.0-2.5 standard deviations below the population mean for age)." (American Psychiatric Association 2013, p. 69).

\section{Criteria for Element 2-Dyslexia Is a Disorder of Written Language}

Dyslexia does not appear to be rooted in the reader's oral language, per se. In fact, most people with dyslexia are accurate and fluent speakers. For the most part, they have difficulty extracting meaning from printed words and sentences that they have previously mastered in speech. This being the case, psychometric tests used to diagnose dyslexia should focus primarily on measuring print knowledge and word reading comprehension. When screening for or diagnosing dyslexia, avoid using tests of decoding or oral language, such as oral reading lists of nonwords or nonsense words, sound blending, sound discrimination, phonological awareness, auditory memory, or other phonemic-based tests that contain no graphemes. These tests yield phonological information that is more useful when identifying specific areas for intervention. Their use in identifying students with dyslexia can, however, result in unwanted numbers of false positives (see Catts et al. 2017).

\section{Criteria for Element 3-Dyslexia Is a Disorder Affecting Word Comprehension}

When selecting a suitable test of word comprehension to identify students with dyslexia, you should only use highly reliable (i.e., estimated alpha .90 or higher) measures of word reading comprehension. Specifically, word reading measures that assess the ability to read words accurately and fluently (either in isolation or context; silently or orally) should be given priority for use as measures of comprehension. Regardless of the measure and format that you choose, be sure to use highly reliable tests or subtests that measure the ability to read printed real words.

\section{Criteria for Element 4-Dyslexia Is Unexpected}

Finally, by definition, the degree of reading impairment should be unexpected when contrasted with other cognitive abilities (e.g., oral language, intellect), cultural opportunity, or emotional factors. Specifically, dyslexia is not the result of intellectual disability; external factors such as economic or environmental disadvantage, chronic abuse, or lack of education; or a neurological event (i.e., stroke or brain injury); or motor, vision, or hearing disorder.

According to the DSM-5, individuals with intellectual disability have scores approximately 2.0 standard deviations or more below the population mean, including a 5-point margin for measurement error. On a test with a mean of 100 and a standard deviation of 15 , we would begin to suspect intellectual disability at standard scores of 75 or lower. To protect against misidentification of dyslexia, students should score 76 standard score points or more on cognitive measures, and their reading comprehension score should be more than 1.0 standard deviation (i.e., 15-29 points) below their cognitive ability score in order to meet the dyslexia likelihood criteria of likely and more than 2.0 standard deviations or more (i.e., 30 or more points) to meet the criteria for very likely. Both groups would be considered at risk for dyslexia.

\section{Method}

In this section, we provide initial empirical evidence to demonstrate the research basis for the revised discrepancy method discussed previously. Included are descriptions of the demographic characteristics of the subjects in the study, the specific measures used to assess reading comprehension and cognitive ability, and the procedures used to classify students as having dyslexia or not.

\section{Selection of Examiners and Subjects}

The examiners were obtained by asking licensed educational diagnosticians, school psychologists, or speech-language 
pathologists currently practicing in their respective fields to collect data on students in their geographic area who are presently enrolled in special services for dyslexia. Because our research is exploratory in nature, no attempt was made to collect a nationally representative sample of students receiving special services for dyslexia. Examiners were simply asked to collect data on students in their area who are officially diagnosed as having dyslexia. We did not ask how and when the students in the sample were originally identified as having dyslexia. Presumably, the identification criteria varied from state to state and from site to site. Similarly, we did not ask how long these students had been enrolled in intervention services for dyslexia. Most certainly this information should be the target of future research.

Three data quality control procedures were employed during data collection:

1. Examiners were required to secure signed parent/guardian permission forms with contact information for each student prior to testing.

2. All the completed Examiner Record Forms were carefully inspected to identify scoring errors and to make sure that basal and ceiling rules were followed.

3. The authors further examined the electronic data via statistical programming for any potential irregularities and corrected the data as needed.

These procedures resulted in a sample of 70 students diagnosed with dyslexia who were between the ages of 7 and 15 years (mean $=10.6$, standard deviation $=2.1$ ) and reside in eight states (Colorado, Maryland, Michigan, Oklahoma, Oregon, Texas, Wisconsin, and West Virginia) and 10 different zip codes. The demographic characteristics of the total sample of 70 students presently being taught under the dyslexia label is provided in Table 1.

\section{Measures}

Three well-known commercially available measures (two reading comprehension measures and one measure of general cognitive abilities) were administered to the sample. The measures are described briefly below.

Reading Measures Two measures of silent reading fluency (i.e., measuring accuracy and rate) were administered to the entire sample: the Test of Silent Word Reading FluencySecond Edition (TOSWRF-2; Mather et al. 2014) and the Test of Silent Contextual Reading Fluency-Second Edition (TOSCRF-2; Hammill et al. 2014). These measures require students to identify unrelated words (TOSWRF-2) or related words within sentences (TOSCRF-2) printed without spaces between the words or any punctuation in the sentences.
Table 1 Demographic characteristics of the sample

\begin{tabular}{|c|c|c|}
\hline Characteristic & Number & Percent \\
\hline \multicolumn{3}{|l|}{ Region } \\
\hline South & 45 & 64 \\
\hline Midwest & 2 & 3 \\
\hline West & 23 & 33 \\
\hline Northeast & 0 & 0 \\
\hline \multicolumn{3}{|l|}{ Gender } \\
\hline Male & 36 & 51 \\
\hline Female & 34 & 49 \\
\hline \multicolumn{3}{|l|}{ Hispanic } \\
\hline Yes & 3 & 4 \\
\hline No & 67 & 96 \\
\hline \multicolumn{3}{|l|}{ Race } \\
\hline White & 67 & 96 \\
\hline Black & 2 & 3 \\
\hline Two or more races & 1 & 1 \\
\hline \multicolumn{3}{|l|}{ Lunch status } \\
\hline Free lunch & 6 & 9 \\
\hline Reduced lunch & 4 & 6 \\
\hline Pays for lunch & 60 & 85 \\
\hline \multicolumn{3}{|l|}{ Type of school } \\
\hline Public & 39 & 56 \\
\hline Private & 31 & 44 \\
\hline \multicolumn{3}{|l|}{ Educational setting } \\
\hline General education & 55 & 79 \\
\hline Special ed/alternative & 9 & 13 \\
\hline Resource room & 2 & 2 \\
\hline Other & 4 & 6 \\
\hline \multicolumn{3}{|l|}{ Exceptionality status } \\
\hline Dyslexia & 70 & 100 \\
\hline ADHD & 24 & 34 \\
\hline LD reading & 17 & 24 \\
\hline LD math & 2 & 3 \\
\hline LD writing & 15 & 21 \\
\hline LD other & 1 & 1 \\
\hline Articulation disorder & 4 & 6 \\
\hline Emotional disturbance & 1 & 1 \\
\hline
\end{tabular}

The manuals of both tests report very large correlations with popular measures of reading comprehension (mean corrected correlation .75; range .41-.92). For example, the average correlation between TOSWRF-2, TOSCRF-2, and the Oral Reading Index from Gray Oral Reading TestsFifth Edition (GORT-5; Wiederholt and Bryant 2012) was .73. The tests also correlated .75 with the Tests of Silent Reading Efficiency and Comprehension (TOSREC; Wagner et al. 2010), .78 with the Sight Word Reading Efficiency from the Test of Word Reading Efficiency (TOWRE; Torgesen et al. 1999), and .73 with the Reading Comprehension score from 
the Stanford Achievement Test Series-Ninth Edition (SAT9; Pearson Assessments 1996). Likewise, both the TOWSRF-2 and the TOSCRF-2 evidence high reliability (median .87 ; range .84-.90), sensitivity (median .78; range .73-.84), specificity (median .79; range .71-.84), and receiver operating characteristic/area under the curve (ROC/AUC; median .88; range .85-.89).

The formats of both tests are based on the works of Guilford (1959); Guilford and Hoepfner (1971); Jacobson (1998); Meeker et al. (1985); and Miller-Guron (1996), who demonstrated that the timed contextual-word-strings-without-spaces format has been successfully used previously to measure word reading accuracy and speed (i.e., fluency). Both tests can be administered in 3 min to entire classrooms or to individual students age 7 years 0 months through 24 years 11 months. They both include four alternate forms that yield standard scores based on a mean of 100 and a standard deviation of 15 .

To improve reliability and diagnostic accuracy of the reading measures, the TOSWRF-2 and TOSCRF-2 scores were combined to create a Silent Reading Ability composite score using Table D.1 in Appendix D, which appears in both the TOSWRF-2 and TOSCRF-2 Examiner's Manuals. The median composite alternate-forms reliability is .93 (range .92-.96).

Cognitive Ability Measure The Detroit Tests of Learning Abilities-Fifth Edition (DTLA-5; Hammill et al. 2018) is an individually administered battery of 12 subtests that measure a broad spectrum of cognitive abilities designed for use with students age 6 years through 17 years. The subtests represent cognitive abilities that are developmental in nature and acquired incidentally as a result of environmental experience or directly as the result of instruction at home or school or self-study. The subtests can be combined to form six subdomain composites:

- Acquired Knowledge (Humanities/social Studies, Science/ Mathematics)

- Verbal Comprehension (Word Opposites, word Associations)

- Nonverbal Problem Solving (Geometric Matrices, Geometric Sequences)

- Verbal Memory (Sentence Imitation, Word Span)

- Nonverbal Memory (Design Reproduction, Reversed Letters)

- Processing Speed (Trail Making, Rapid Naming)

The subtests that form the subdomain composites also can be combined to form two domain composites, Reasoning Ability (includes the Acquired Knowledge, Verbal Comprehension, and Nonverbal Problem solving subdomain composites) and Processing Ability (includes the Verbal Memory, Nonverbal Memory, and Processing Speed subdomain composites). Finally, the entire battery of subtests can be combined to form a General Cognitive Ability composite.

The DTLA-5 was standardized on a sample of 1383 students who were representative of the nation as a whole regarding geographic region, gender, race, Hispanic status, exceptionality status, parent education, and family household income. Internal consistency reliability for the subtests ranged from .79 to .92 and for the subdomains the composites ranged from .87 to .95 . The Reasoning Ability composite reliability was .97 and the Processing Ability composite reliability was 95. The General Cognitive Ability composite reliability was 98. The DTLA-5's median diagnostic accuracy when identifying students as gifted and talented using a cut score of 110 was sensitivity $=.77$, specificity $=.72$, and $\mathrm{ROC} / \mathrm{AUC}=.83$. The diagnostic accuracy when identifying students with an intellectually disability using a cut score of 70 was sensitivity $=.89$, specificity $=.97$, and $\mathrm{ROC} / \mathrm{AUC}=.99$. Average correlations (corrected for range effects and attenuation) of the DTLA-5 with five popular commercially available measures of cognitive abilities for the Reasoning Ability, Processing Ability, and General Cognitive Ability were .72, .78, and .80 , respectively.

We compared the Silent Reading Ability composite score to the DTLA-5's Reasoning Ability, Processing Ability, and General Cognitive Ability composite scores. We found very similar results in all cases; we chose to use the Reasoning Ability composite score as the estimate of cognitive ability in this paper because it was the most theoretically pleasing to us.

\section{Procedures}

We were interested in the discrepancy method because it very clearly and efficiently operationalizes the common element of the unexpected nature of the below-average reading ability found in most definitions of dyslexia. We recognized, however, that the traditional discrepancy method has shortcomings. In an effort to improve upon the traditional discrepancy method, we created a revised discrepancy method based on common elements of the definitions for dyslexia, such as (a) a cut score floor for cognitive ability, (b) a cut score ceiling for reading ability, and (c) probability levels for likelihood of dyslexia.

Many researchers (e.g., Fisher and DeFries 2002; Grigorenko 2005; Plomin and Kovas 2005; Shaywitz et al. 1992; Stanovich 1988; Wagner 2018) have suggested that specific reading disability (including dyslexia) lies on a continuum and have advocated for recognizing degrees or probability levels for dyslexia rather than a single cut score yielding a dichotomous classification. Most recently, Fletcher et al. (2018) suggested that "identification [of dyslexia] may be improved by moving away from [dichotomous] categorical decisions and considering the likelihood or probability of LD, 
or more importantly the likelihood that a person would benefit from intervention" (p. 58).

Rather than treating dyslexia as a binary condition (i.e., you have it or you do not), we followed the suggestion of Fletcher et al. (2018) and assigned students to three categories of likelihood for dyslexia: very likely, likely, and not very likely. These are referred to as the three probability of dyslexia categories:

- Very likely: Students with Reasoning Ability standard scores of 76 points or more, Silent Reading Ability standard scores of 84 points or less, and Silent Reading Ability scores that were 30 points or more below the Reasoning Ability scores were included in this group.

- Likely: Students with Reasoning Ability standard scores of 76 points or more, Silent Reading Ability scores of 84 points or less, and Silent Reading Ability scores that were 15 to 29 points below the Reasoning Ability scores were included in this group.

- Not very likely: Students with Reasoning Ability standard scores of 75 points or less, or Silent Reading Ability standard scores of 85 points or more, or Silent Reading Ability scores that were 14 points or less below the Reasoning Ability scores were included in this group.

\section{Results}

In this section, we review the results of using our revised discrepancy method to reclassify the 70 students previously identified as having dyslexia into one of the three probability of dyslexia categories. Specifically, we discuss the demographic characteristics and the scores made by the students in each of the three categories.

\section{Student Demographics in the Three Probability of Dyslexia Categories}

In this study, we wanted to learn how well our revised discrepancy method for identifying students with dyslexia would match a sample of 70 students currently receiving educational services in schools under the dyslexia label. Therefore, we used our revised discrepancy method to reclassify the 70 students previously identified as having dyslexia into one of the three probability of dyslexia categories. The demographic characteristics for the three probability of dyslexia categories are presented in Table 2.

Based on our revised discrepancy method, 16 students met the criteria for the very likely category, 20 students met the criteria for the likely category, and 34 students met the criteria for the not very likely category. It is worth noting that $49 \%$ of the students were categorized as not very likely to have
Table 2 Demographics of the sample based on probability of dyslexia

\begin{tabular}{|c|c|c|c|}
\hline \multirow[t]{2}{*}{ Characteristic } & \multicolumn{3}{|c|}{ Probability of dyslexia } \\
\hline & $\begin{array}{l}\text { Very likely } \\
(n=16)\end{array}$ & Likely $(n=20)$ & $\begin{array}{l}\text { Not very likely } \\
(n=34)\end{array}$ \\
\hline State & $\begin{array}{l}\mathrm{CO}, \mathrm{MD}, \\
\text { OR, TX }\end{array}$ & $\begin{array}{l}\mathrm{CO}, \mathrm{MD}, \mathrm{OK}, \\
\text { TX, WI, WV }\end{array}$ & $\begin{array}{l}\text { CO, MD, MI, OK, } \\
\text { OR, TX, WV }\end{array}$ \\
\hline \multicolumn{4}{|l|}{ Region } \\
\hline South & 10 & 15 & 20 \\
\hline Midwest & 0 & 1 & 1 \\
\hline West & 6 & 4 & 13 \\
\hline Northeast & 0 & 0 & 0 \\
\hline $\begin{array}{l}\text { Age range (in } \\
\text { years) }\end{array}$ & $7-15$ & $7-15$ & $8-15$ \\
\hline \multicolumn{4}{|l|}{ Gender } \\
\hline Male & 12 & 11 & 13 \\
\hline Female & 4 & 9 & 21 \\
\hline \multicolumn{4}{|l|}{ Hispanic } \\
\hline Yes & 0 & 1 & 2 \\
\hline No & 16 & 19 & 32 \\
\hline \multicolumn{4}{|l|}{ Race } \\
\hline White & 16 & 20 & 30 \\
\hline Black & 0 & 0 & 2 \\
\hline $\begin{array}{l}\text { Two or more } \\
\text { races }\end{array}$ & 0 & 0 & 1 \\
\hline \multicolumn{4}{|l|}{ Lunch status } \\
\hline Free lunch & 0 & 4 & 2 \\
\hline Reduced lunch & 1 & 2 & 1 \\
\hline Pays for lunch & 15 & 14 & 31 \\
\hline \multicolumn{4}{|l|}{ Type of school } \\
\hline Public & 5 & 13 & 21 \\
\hline Private & 11 & 7 & 13 \\
\hline \multicolumn{4}{|l|}{ Educational setting } \\
\hline $\begin{array}{l}\text { General } \\
\text { education }\end{array}$ & 12 & 15 & 24 \\
\hline $\begin{array}{l}\text { Special } \\
\text { ed/alternative }\end{array}$ & 3 & 3 & 3 \\
\hline Resource room & 0 & 1 & 1 \\
\hline Other & 1 & 0 & 3 \\
\hline Missing & 0 & 1 & 3 \\
\hline \multicolumn{4}{|l|}{ Exceptionality } \\
\hline Dyslexia & 16 & 20 & 34 \\
\hline $\mathrm{ADHD}$ & 6 & 7 & 11 \\
\hline LD reading & 5 & 5 & 7 \\
\hline LD math & 1 & 0 & 1 \\
\hline LD writing & 5 & 5 & 5 \\
\hline LD other & 0 & 0 & 1 \\
\hline $\begin{array}{l}\text { Articulation } \\
\text { disorder }\end{array}$ & 1 & 2 & 1 \\
\hline $\begin{array}{l}\text { Emotional } \\
\text { disturbance }\end{array}$ & 1 & 0 & 0 \\
\hline
\end{tabular}

dyslexia according to our revised discrepancy method. As expected, the percentage of males $(75 \%)$ versus females 
$(25 \%)$ in the very likely probability category is consistent with the 2:1 to 3:1 male-to-female representation reported in the DSM-5. The percentage of males $(53 \%)$ versus females $(48 \%)$ in the likely probability category was more evenly split. The percentage of males $(40 \%)$ versus females $(60 \%)$ in the not very likely probability category is the opposite of what one would expect in a sample of students with dyslexia.

The fact that $11(69 \%)$ of the students in the very likely probability category attend private schools could mean that (a) the parents of seriously impaired students with dyslexia are more likely to send their children to private schools than are parents of mild-to-moderately impaired students or (b) the parents of seriously impaired students with dyslexia are more financially affluent than the parents of students in the other groups. In any event, this finding is not surprising given the parent and professional advocacy for special services and more customized treatment for students with dyslexia.

Because the sample included a wide age range of students, we divided the sample into two age groups (7-10 years and 11-15 years). We examined the data for any systematic difference in how each group was categorized by the revised discrepancy method. We found that each age group was roughly equally represented in all three probability levels for dyslexia.

\section{Student Performance in Each Probability-of-Dyslexia Category}

Table 3 provides a score overview of the students in each probability of dyslexia category. In this table, we provide our own terms to describe the three levels of discrepancy. We describe students with reading-reasoning difference scores of 14 standard score points or less as insufficient for a dyslexia diagnosis, between 15 and 29 points as minimally acceptable, and 30 points or more as acceptable. When viewing the scores for the total sample (at the bottom of the table), one may reasonably conclude that, taken as a whole, the 70-case sample is minimally acceptable. While this finding is encouraging and interesting, it does not tell the whole story. A closer look at the table's content indicates that $50 \%$ of the sample is not very likely to have dyslexia because, taken as a whole, this category does not pass the "unexpectedness" or "severity" criteria because the average difference between their reading and reasoning scores is only 7.68 points and their average reading score is 91.76 ("low average").

Our readers will find the data reported in Tables 4, 5 and 6 to be much more interesting. In these tables, we share with you the actual scores of each student in the three probability of dyslexia categories. Basically, we are sharing our data set with you. After parsing these scores, you can decide for yourself whether our three levels of dyslexia make good sense to you or not.

Table 4 shows the scores of 16 students who met the dyslexia probability criteria for very likely. All 16 students have reading standard scores of 83 or less (average $=65$, range $=$ $50-83$ ), reasoning standard scores of 88 points or more (average $=103$, range $=88-122$ ), and difference scores of 30 points or more (average $=38$, range $=30-53$ ). These students satisfy all three of our criteria for dyslexia. Most professionals working in dyslexia would probably agree that these students are very likely to have dyslexia.

Table 5 shows the scores of 20 students who met the dyslexia probability criteria for likely. All 20 of the students have reading scores less than 85 (average $=76$, range $60-84$ ), reasoning scores more than 75 (average $=99$, range $=84-108$ ) and difference scores of 15 to 29 points (average $=23$, range $=$ 15-29). These students pass the minimally acceptable criteria for identification as having dyslexia in our system.

Table 6 shows the scores of the 34 students who met the dyslexia probability criteria for not very likely. Twenty-six of these students failed the severity criterion (i.e., their reading scores were above 84; average $=92$, range 77-112). In fact, six $(17 \%)$ students had reading scores higher than their reasoning scores! Six cases are obviously problematic: \#44, \#50, $\# 55$, \#56, \#57, and \#58. All six of these students passed the cognitive criterion (i.e., their reasoning composite scores were 76 points or more) and the unexpectedness criterion (i.e., their difference scores were 15 points or more) but failed the severity criterion.

We looked for statistical discrepancies among the DTLA-5 subdomain scores for the three probability of dyslexia

Table 3 Sample size, percentages, and average standard scores by probability for dyslexia category

\begin{tabular}{llllll}
\hline Probability of dyslexia & Number & Percent & Average standard scores & \\
\cline { 4 - 6 } & & & Reading $^{\mathrm{a}}$ & Reasoning $^{\mathrm{a}}$ & Difference $^{\mathrm{b}}$ \\
\hline Very likely & 16 & 22.9 & 65.38 (Mildly impaired or delayed) & 102.87 (Average) & 37.50 (Acceptable) \\
Likely & 20 & 28.6 & 75.50 (Borderline impaired or delayed) & 98.50 (Average) & 22.95 (Minimally acceptable) \\
Not very likely & 34 & 48.6 & 91.76 (Average) & 99.44 (Average) & 7.68 (Insufficient) \\
Total sample & 70 & 100 & 81.10 (Low average) & 99.96 (Average) & 18.86 (Minimally acceptable) \\
\hline
\end{tabular}

${ }^{\text {a }}$ Descriptive terms are borrowed from the Stanford-Binet Intelligence Scales-Fifth Edition (Roid 2003)

${ }^{\mathrm{b}}$ Difference score $<15$ = insufficient; difference score 15-29= minimally acceptable; difference score $>29=$ acceptable 


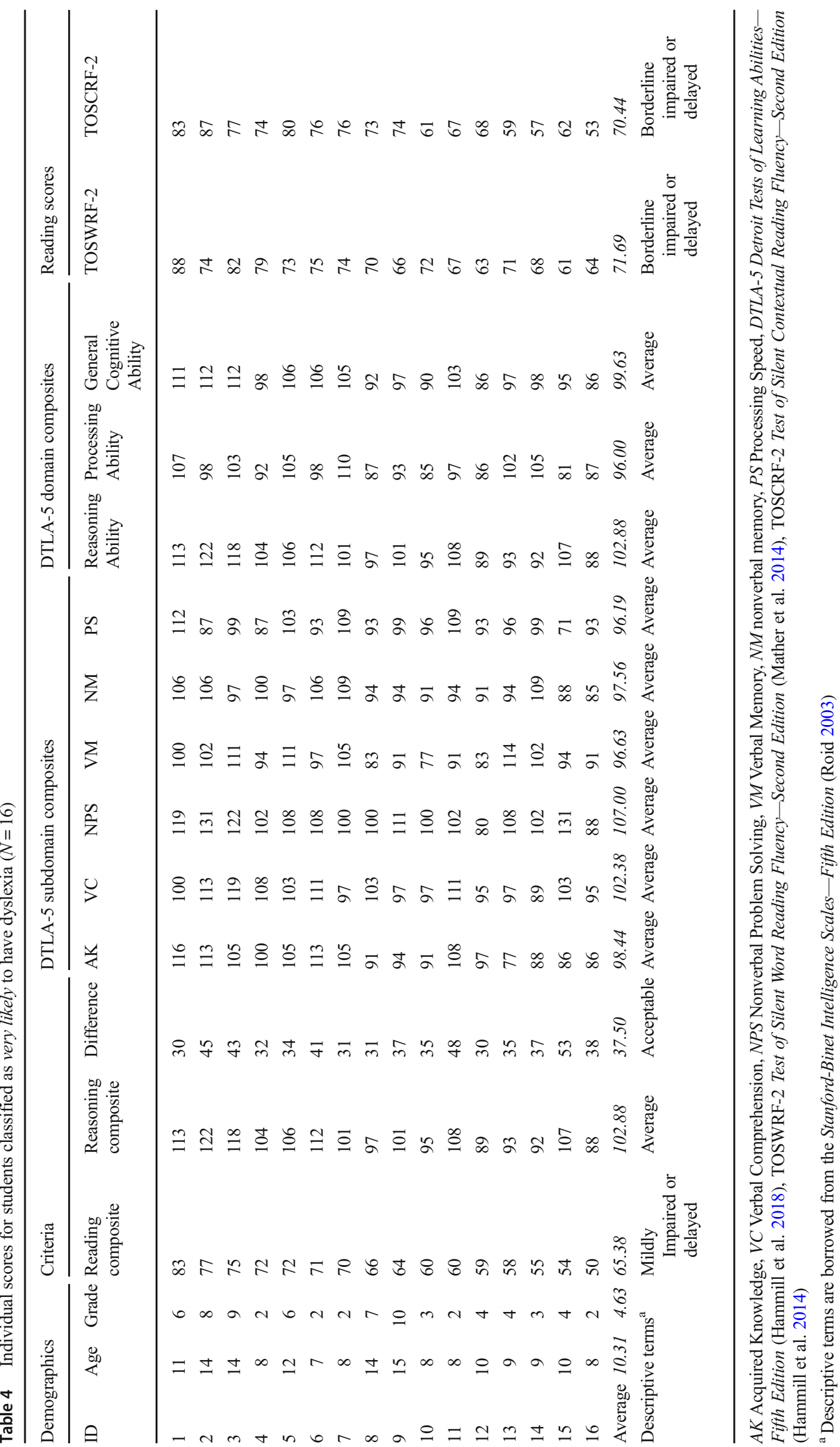




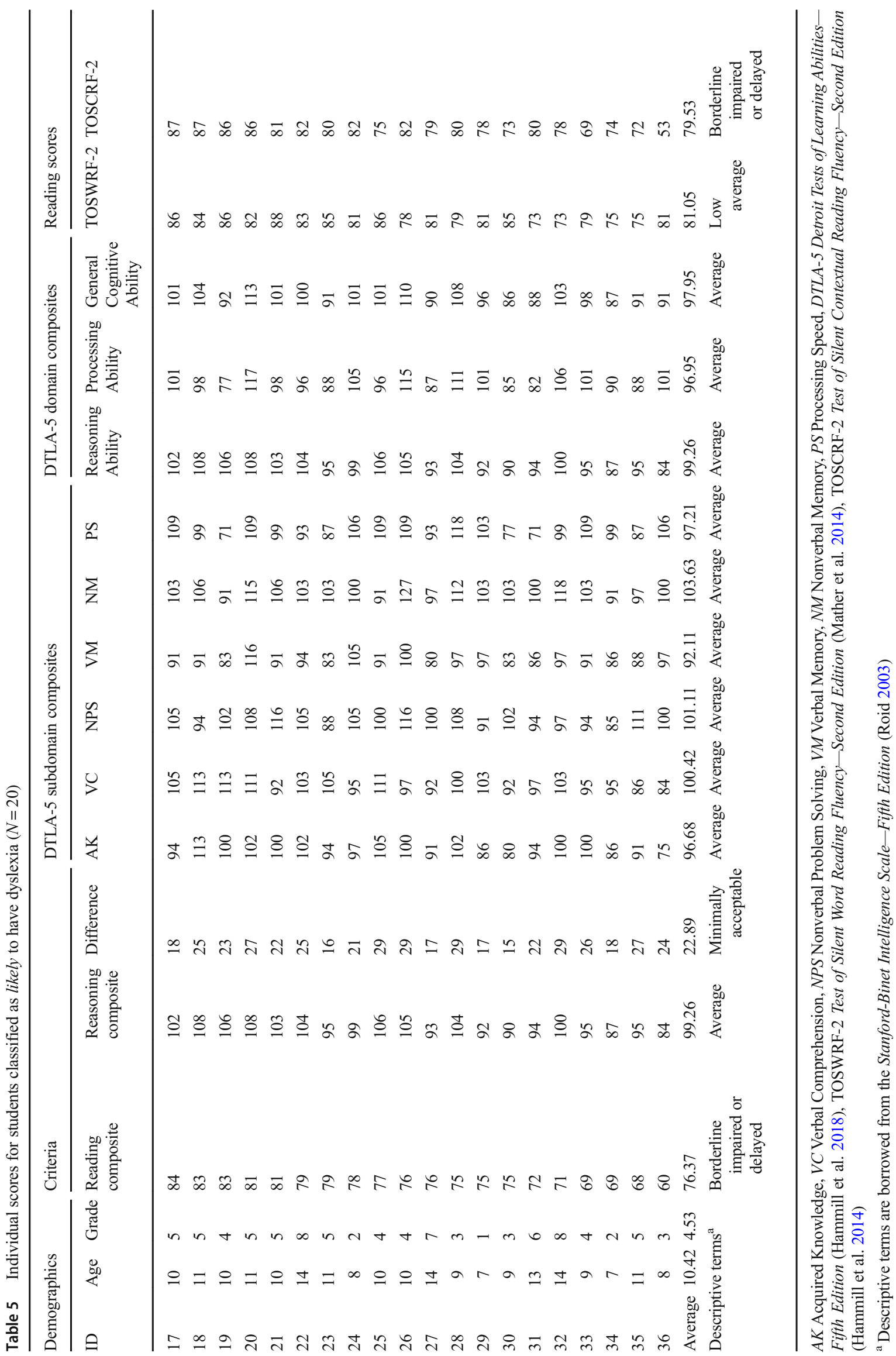




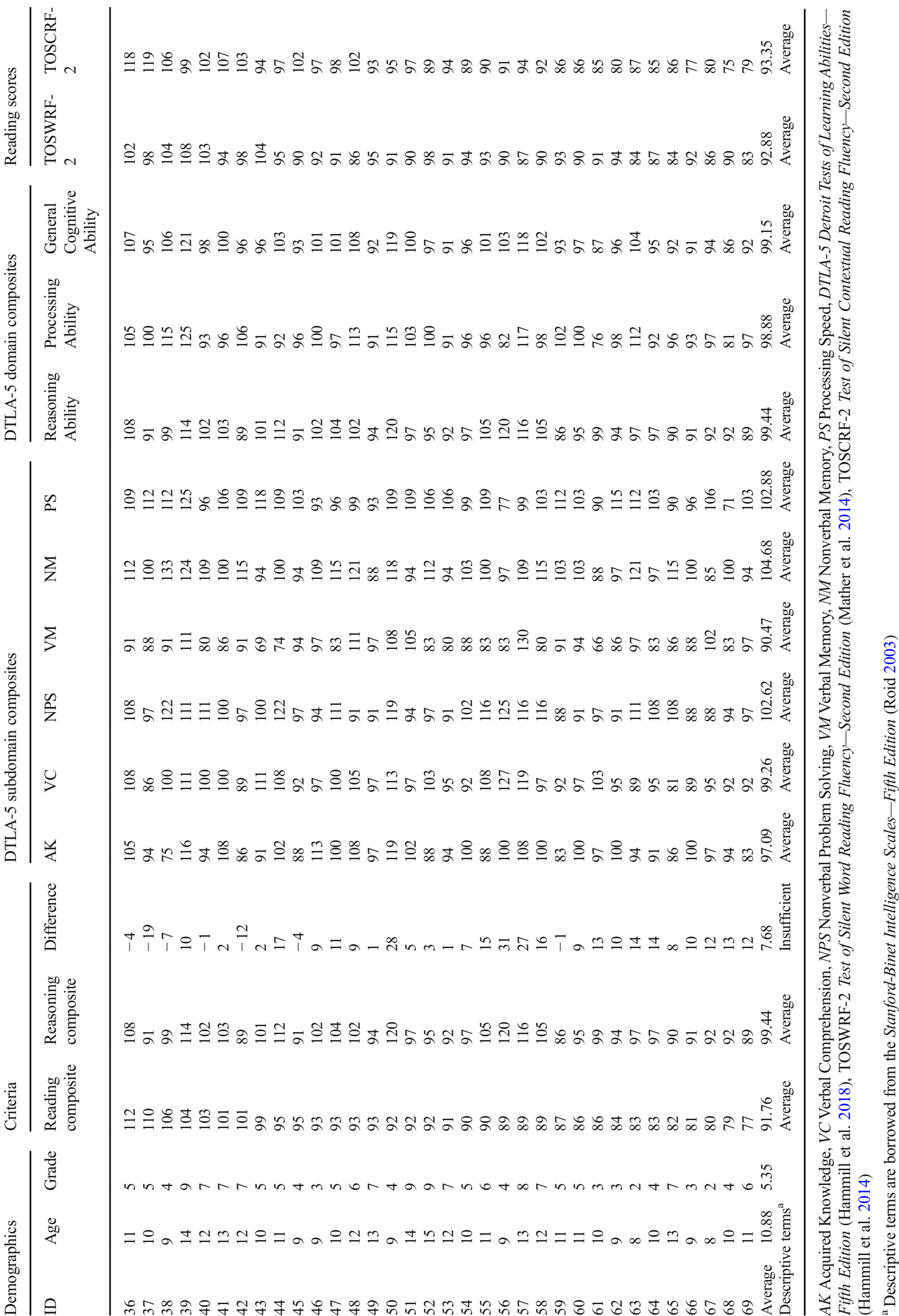


categories by using a pairwise comparison method. Taken as a group, we found no consistent pattern of cognitive strengths and weaknesses. On the individual level, some students did have clinically useful differences among abilities.

\section{Discussion}

In this section, we discuss the results of our study. Specifically, we (a) review the implications of this study for research and practice, (b) discuss the implications of reading correlates in identifying dyslexia, (c) review the implications for future directions and the study's limitations, and (d) offer some conclusions.

\section{Implications for Research and Practice}

The common wisdom today is that the field of learning disabilities (LDs) and dyslexia is fraught with false positives and false negatives (Adelman 1992; Fletcher et al. 2014; Fletcher et al. 2018; Wagner 2018). In their prophetic article, Learning Disabilities: A Field in Danger of Extinction?, Mather and Roberts (1994) noted that "failure to discriminate LDs from other learning problems perpetuates misdiagnosis and threatens the integrity of the field" (p. 56).

The revised discrepancy method described in this study can be used by researchers to identify students in their studies who have dyslexia and that most researchers might agree are prototypical examples of dyslexia (i.e., low reading ability, higher cognitive ability, and a difference of more than 1.0 standard deviation between the two scores). Currently, researchers rarely report in any detail how their samples are verified as having dyslexia. Without replicable dyslexia criteria, we can never be sure that any two studies of dyslexia are examining the same kind of subjects.

When selecting a sample of students with dyslexia for $r e-$ search purposes, reading and cognitive ability cut points should be inflexibly applied because false negatives are less detrimental to the research results than false positives. Because questionable or problematic cases might or might not have dyslexia, they should be excluded in research samples. Research samples need to be as pure as possible. For research purposes, arbitrary cut points are an asset because gold standard samples are required in order to have confidence in the validity of the research.

When identifying students with dyslexia for educational services in schools, we agree with Fletcher et al. (2018) that the cut points can be more flexible "or that confidence intervals be used around a particular cut point because false positive errors are less detrimental than false negative errors" ( $p$. 59). In this case, arbitrary cut points are a detriment, but one that can be minimized. An examiner might use a confidence interval such as a standard error of estimation $\left(S E_{\mathrm{E}}\right)$ around the cut scores to mitigate the effects of measurement error associated with the scores. $S E_{\mathrm{E}}$ provides a band of error that reflects regression effects resulting in confidence intervals that are typically not symmetrically distributed around the obtained score (except those near the mean) but, rather, extend more toward the mean than away from the mean. See Salvia et al. (2017) for further discussion of this topic.

Strictly speaking, the cases we have categorized as not very likely to have dyslexia do not meet our revised discrepancy criteria, but the identification of students to receive services should not be based on test results alone. Most current authorities (e.g., Flanagan et al. 2013; Fletcher et al. 2018; Wagner 2018) would probably agree that the identification of students with specific reading disabilities or dyslexia should not be based on a single factor (e.g., discrepancy between cognitive ability and reading achievement, severity of reading failure). Instead, they would likely recommend that diagnostic efforts should incorporate other important factors, as well. Any factors that lead to low achievement, including inclusion and exclusion criteria for dyslexia, need to be considered as part of a comprehensive evaluation. In the end, no methodology will eliminate all false positives or false negatives. Clinical judgment made by a qualified professional will always have an important role to play in the identification of students with dyslexia. A multifaceted approach should result in a more complete understanding of this disabling condition. In short, while all students with dyslexia are very poor readers, not all (or even most) poor readers have the condition. An important aim of a comprehensive evaluation should be to make that distinction.

\section{Implications of Reading Correlates in the Identification and Instruction of Dyslexia}

Many professionals believe that deficits in phonological (i.e., speech sounds) processing - specifically phonological awareness and oral vocabulary - cause difficulties in learning to decode, which leads to poor comprehension of printed words. However, the research in this area is far from convincing. In fact, Catts and Petscher (2018) noted that "some children with dyslexia have no history of phonological deficits and many children with phonological deficits do not develop dyslexia" (p. 33).

It is not enough for professionals to assert that phonological deficits are significantly related to reading; they must demonstrate (a) that the presence of these deficits is a reliable, valid, and useful predictor of dyslexia and/or (b) that the training of phonological skills results in meaningful improvement in reading comprehension. Relative to the first point, we recommend reading Developmental Relationship between Language and Reading: Reconciling a Beautiful Hypothesis with Some Ugly Facts (Scarborough 2005). In her paper, Scarborough presents evidence and concludes that the 
phonological model has many inconsistencies and is incomplete in accounting for the relationship of oral to written language difficulties.

For the second point, we recommend reading the Reading First Impact Study, Final Report (Gamse et al. 2008). The Reading First Impact Study sought to evaluate the effects of the Federally-funded Reading First Initiative, which emphasized (a) reading curricula and materials focusing on phonemic awareness, phonics, vocabulary, fluency, and comprehension; (b) professional development and coaching for teachers on scientifically based reading practices and how to work with struggling readers; and (c) diagnosis and prevention of reading difficulties through early screening, intervention, and monitoring. The study followed students and teachers at 17 school districts and one state-wide program from first through third grade. The only meaningful findings of this study were that (a) teachers spent significantly more instructional time on phonemic awareness, phonics, vocabulary, fluency, and comprehension in grades one and two, and (b) teachers received significantly more professional development in scientifically based reading instruction, more support from full-time reading coaches, and more supports for struggling readers. The study found, however, that in spite of all of the additional instructional time and training, the Reading First Initiative had no statistical impact on student engagement with print or on the students' reading comprehension. Further, student decoding was only marginally improved (effect size 0.17 ).

A very powerful statistical methodology has been used to investigate the usefulness of phonological and graphophonemic abilities in identifying poor readers is called diagnostic accuracy analysis (i.e., the computation of a test's sensitivity and specificity, and receiver operating characteristic/area under the curve [ROC/AUC]). To date, at least five studies have investigated the value of phonological or graphophonological measures to accurately identify poor readers: Hammill et al. (2002); Johnson et al. (2009); Nelson (2009); Riedel (2007); Torgesen et al. (2012); and Wilson and Lonigan (2010). Even though each study used different measures of print knowledge, phonological awareness, graphophonemic skills, decoding, and oral vocabulary to screen for poor readers, their conclusions were basically the same - the inclusion of phonological measures did not improve the accuracy of identifying poor readers to a level above that of the print reading measure alone. That said, phonological measures do have legitimate uses, such as identifying individuals who have other phonological processing difficulties, such as with rhyming, segmenting sounds in words, blending phonemes, and discriminating between speech sounds. However, the role of phonological measures in predicting poor readers and identifying readers with dyslexia is not yet settled science.

Because the role that phonological factors play in dyslexia seems unclear at the present time, we did not consider them to represent "reading" in our dyslexia identification system. Instead, we used measures of real word reading in isolation and context, a choice consistent with the dyslexia definitions listed earlier in this paper and with a considerable amount of existent empirical research (some of which is reported in this paper).

We recommend that examiners wait to assess phonological skills until after a dyslexia diagnosis has been made. Information about the status of students' phonological skills is probably helpful when preparing individual intervention programs because some (many) young students do have problems associating sounds with letters and printed words. Not all phonological skills, however, are related to reading (not even remotely). In fact, most students with dyslexia are linguistically proficient for their age in that they can generate unique spoken sentences, understand the sophisticated speech of others, and speak without problems of prosody or articulation.

\section{Implications for Future Directions and Limitations of the Study}

In this paper, the authors have proposed a revised discrepancy method for identifying students with dyslexia to serve as subjects in research studies and perhaps to qualify students for intervention services. It is not a perfect system and probably could be improved. It was not our intention to settle the issue of how to identify dyslexia. Instead, our goal is to open up and extend discussions dealing with how to create identification criteria that are valid and efficient. At present, our findings are best described as plausible, interesting, and perhaps provocative. We leave it to future research to validate this method with larger samples of students and address additional issues using a variety of reading and cognitive ability measures. Future research will need to investigate the validity of all dyslexia identification systems that are proposed. These systems will use different measures of reading and cognition than we used. Most of the new tests being built to identify dyslexia today will likely include the data needed to validate our system (and those of others).

The method presented in this paper is a revised discrepancy method and is just one way to operationally define dyslexia. Our revised discrepancy method allows professionals a way to quickly and reliably estimate the level of unexpectedness of the poor reading ability of a particular student, something that cannot confidently be done without examining the cognitive ability of students with low reading ability. Many other ways of identifying dyslexia are possible, such as instructional response, low achievement, cognitive discrepancy, and intraindividual differences (for more details, see Fletcher et al. 2018). An advantage of our system is that it yields levels of probability of having dyslexia.

Our system may appear to involve a lot of testing time, but most students who are referred for reading problems have 
already been tested using reading and cognitive batteries. The methodology presented here would allow for the use of current school file data to quickly and more accurately identify students with possible dyslexia. That said, do not be alarmed if further testing is required. Most examiners find the information gathered in the evaluation process useful. In the end, this paper presents a feasibility study to determine whether the development of useful criteria is possible and valid. The answer is "yes." Given the current interest in dyslexia, many other identification systems will likely be forthcoming.

\section{Conclusions}

For the past 60 years (more or less), dyslexia has been considered a type of learning disorder, referred to as "specific reading disability" or "specific learning disorder with impairment in reading." It is likely that the growing interest in dyslexia today is a reflection of a growing dissatisfaction with the present state of learning disabilities in the USA, especially as it pertains to dyslexia. Perhaps the dyslexia people have a point! It is a well-known fact that no matter what criteria are actually being used currently to identify specific reading disabilities/dyslexia, those practices are making little or no distinction between readers with dyslexia and garden variety poor readers. Both the dyslexia and the specific learning disabilities professionals and parents should welcome the newfound interest in dyslexia by the state and federal governments. Perhaps one of the results will be the adoption of widely accepted diagnostic criteria that will allow clinicians and assessment professionals to accurately separate individuals with dyslexia from other poor readers.

At present, neither the learning disabilities nor dyslexia fields have any close-to-universally accepted criteria for identifying specific students who need clinical/educational intervention or who can serve as subjects in studies investigating dyslexia (or specific reading disability). Without such criteria, no scientific study in the field is possible because no study can be properly replicated. Barbara Bateman (1992) cautioned us almost 30 years ago that "the fact that many diagnosticians do not distinguish learning disabilities from generic low performance does not mean it cannot be done" (p. 32). We are still working on it, Barbara!

Authors' Contributions Both authors contributed to the study conception and design. Material preparation, data collection, and analysis were performed by Elizabeth A. Allen. The first draft of the manuscript was written by Donald D. Hammill and Elizabeth A. Allen, and both authors commented on previous versions of the manuscript. Both authors read and approved the final manuscript.

Data Availability The data are included in the manuscript.

\section{Compliance with Ethical Standards}

Competing Interests The authors of this paper are also authors of the measures used in this study.

\section{Appendix}

\section{Definitions of Dyslexia}

Merriam-Webster's Collegiate Dictionary (n.d.). Dyslexia: A variable, often familial, learning disability involving difficulties in acquiring and processing language that is typically manifested by a lack of proficiency in reading, spelling, and writing.

American Heritage Dictionary of the English Language (n.d.). Dyslexia: A learning disorder marked by impairment of the ability to recognize and comprehend written words.

A Comprehensive Dictionary of Psychological Terms: A Guide to Usage. Dyslexia: Impairment of the ability to read or to understand what one reads silently or aloud, independent of any speech defect (English \& English, 1957, pp. 167).

Dictionary of Behavioral Science (2nd ed.). Dyslexia: A reading disorder characterized by the inability to understand what one reads either silently or aloud (Wolman, 1989, p. 102).

APA College Dictionary of Psychology. Dyslexia: A neurologically based learning disability manifested as severe difficulties in reading, spelling, and writing words, resulting from the impairment of the ability to make connections between written letters and their sounds ... [ [and] is independent to intellectual ability, and is unrelated to disorders of speech and vision that may also be present (American Psychological Association, 2016, p. 112).

Diagnostic and Statistical Manual of Mental Disorders, (5th ed.). Specific Learning Disability/Dyslexia: [Characterized by] inaccurate or slow and effortful word reading (e.g., reads single words aloud incorrectly or slowly and hesitantly, frequently guesses words, has difficulty sounding out words) ... . [has] difficulty understanding the meaning of what is read (e.g., may read text accurately but not understand the sequence, relationships, inferences, or deeper meanings of what is read). The affected academic skills are substantially and quantifiably below those expected for the individual's chronological age, and cause significant interference with academic or occupational performance, or with activities of daily living, as confirmed by individually administered standardized achievement measures and comprehensive clinical assessment. The learning difficulties are not better accounted for by intellectual disabilities, uncorrected visual or auditory acuity, other mental or neurological disorders, psychosocial adversity, lack of proficiency in the language of academic instructions, or inadequate educational instruction (American Psychiatric Association, 2013, pp. 66-67). 
International Statistical Classification of Diseases and Related Health Problems. Developmental Dyslexia: A cognitive disorder characterized by an impaired ability to comprehend written and printed words or phrases despite intact vision. This condition may be developmental or acquired. Developmental dyslexia is marked by reading achievement that falls substantially below that expected given the individual's chronological age, measured intelligence, and age-appropriate education. The disturbance in reading significantly interferes with academic achievement or with activities of daily living that require reading skills. A learning disorder characterized by an impairment in processing written words. Reading difficulties can include distortions, omissions or substitutions of characters. Oral and silent reading difficulties can include faulty and slow comprehension. A learning disorder marked by impairment of the ability to recognize and comprehend written words. Condition characterized by deficiencies of comprehension or expression of written forms of language. Inability or difficulty reading, spelling, or writing words despite the ability to see and recognize letters; a familial disorder with autosomal dominant inheritance that occurs more frequently in males. (American Medical Association, 2018)

Merriam-Webster Medical Dictionary. Dyslexia: A variable often familial learning disability involving difficulties in acquiring and processing language that is typically manifested by a lack of proficiency in reading, spelling, and writing (retrieved on 9/6/2018 from https://www.merriam-webster.com/ dictionary/dyslexia)

A Dictionary of Language (2nd ed.). Dyslexia: A serious disturbance in the ability to read. The term is used both for literate adults who lost their reading ability after brain injury (acquired dyslexia), and for children who encounter special difficulties as they try to learn to read, in the absence of evident brain injury (developmental dyslexia). The term alexia replaces dyslexia in many (especially American) studies, and from time to time several other terms have been used for the condition, such as "word blindness." A commonly associated disorder is dysgraphia (or agraphia), a disturbance in the normal ability to write (Crystal, D., 2001, pp. 95-96).

Terminology of Communication Disorders, SpeechLanguage-Hearing. Alexia: Inability to read; may be the result of neurological impairment; in a less severe form, often referred to as dyslexia. Syn: word blindness (Nicolosi, Harryman, \& Kresheck, 1989, p. 6).

Dictionary of Special Education and Rehabilitation. Dyslexia: An impairment in reading ability, or partial inability to read; often associated with cerebral dysfunction or minimal brain dysfunction. An individual with this condition does not understand clearly what he or she reads. A more generic term for learning problems including dyslexia is learning disability (Kelly \& Vergason, 1978, p. 46).

Dictionary of Developmental Disabilities. Dyslexia: Reading disability, a term loosely employed to describe any learning disability in which reading, writing, and spelling are more severely involved than other areas (Pasquale, Whitman, \& Whitman, 2002, pp. 129-130).

World Federation of Neurology. Dyslexia: A language disorder in children who, despite conventional classroom experience, fail to attain language skills of reading, writing, and spelling commensurate with their intellectual abilities (1968).

International Dyslexia Association. Dyslexia: Dyslexia is a specific learning disability that is neurological in origin. It is characterized by difficulties with accurate and/or fluent word recognition and by poor spelling and decoding abilities. These difficulties typically result from a deficit in the phonological component of language that is often unexpected in relation to other abilities and the provision of effective classroom instruction. Secondary consequences may include problems in comprehension and reduced reading experience that can impede growth of vocabulary and background knowledge (2002).

Dyslexia Defined. Developmental Dyslexia: Developmental dyslexia is a learning disability which initially shows itself by difficulty learning to read, and later by erratic spelling and lack of facility in manipulating written as opposed to spoken words. The condition is cognitive in essence, and usually genetically determined. It is not due to intellectual inadequacy, or to lack of socio-cultural opportunity, or to emotional factors, or to any known brain defect (Critchley \& Critchley, 1978, p. 149).

Developmental Dyslexia: Studies in Disorders of Communication (2nd ed.). Developmental dyslexia is a severe difficulty with the written form of language independent of intellectual, cultural and emotional causation. It is characterized by the individual's reading, writing and spelling attainments being well below the level expected based on intelligence and chronological age. The difficulty is a cognitive one, affecting these language skills associated with the written form, particularly visual to verbal coding, short-term memory, order perception and sequencing. This definition describes dyslexia as a sub-category of written language problem (Thomson, 1984, p. 3).

Open Access This article is licensed under a Creative Commons Attribution 4.0 International License, which permits use, sharing, adaptation, distribution and reproduction in any medium or format, as long as you give appropriate credit to the original author(s) and the source, provide a link to the Creative Commons licence, and indicate if changes were made. The images or other third party material in this article are included in the article's Creative Commons licence, unless indicated otherwise in a credit line to the material. If material is not included in the article's Creative Commons licence and your intended use is not permitted by 
statutory regulation or exceeds the permitted use, you will need to obtain permission directly from the copyright holder. To view a copy of this licence, visit http://creativecommons.org/licenses/by/4.0/.

\section{References}

Adelman, M. J. (1989). Beyond the learning mystique: an interactional perspective on learning disabilities. Journal of Learning Disabilities, 22, 301-304. https://doi.org/10.1177/002221948902200509.

Adelman, M. J. (1992). LD: the next 25 years. Journal of Learning Disabilities, 25, 17-22. https://doi.org/10.1177/002221949202500103.

American Psychiatric Association. (2013). Diagnostic and statistical manual of mental disorders (5th ed.). Washington, appi.books.9780890425596.

American Psychological Association. (2016). APA college dictionary of psychology (2nd ed.). Washington: Author.

Bateman, B. (1992). Learning disabilities: the changing landscape. Journal of Learning Disabilities, 25, 29-36. https://doi.org/10. 1177/002221949202500105.

Catts, H. W., Mcllraith, A., Sittner Bridges, M., \& Corcoran Nielsen, D. (2017). Viewing a phonological deficit within a multifactorial model of dyslexia. Reading and Writing: An Interdisciplinary Journal, 30, 613-629. https://doi.org/10.1007/s11145-016-9692-2.

Catts, H. W., \& Petscher, Y. (2018). Early identification of dyslexia: current advancements and future directions. Perspectives on Language and Literacy, 44, 33-36.

Critchley, M., \& Critchley, E. (1978). Dyslexia defined. London: London Heinemann Medical Books.

Crystal, D. (2001). A dictionary of language (2nd ed.). Chicago: University of Chicago Press.

DeLoach, T. F., Earl, J. M., Brown, B. S., Poplin, M. S., \& Warner, M. M. (1981). L.D. teachers' perceptions of severely learning disabled students. Learning Disability Quarterly, 4, 343-353. https://doi.org/10. 2307/1510736.

Deutsch, G. K., Dougherty, R. F., Bammer, R., Siok, W. T., Gabrieli, J. D., $\&$ Wandell, B. (2005). Children's reading performance is correlated with white matter structure measured by diffusion tensor imaging. Cortex, 41, 354-363. https://doi.org/10.1016/S0010-9452(08) 70272-7.

dyslexia (n.d.-a). In American heritage dictionary of the English language. Retrieved from https://ahdictionary.com/word/search. $\mathrm{html}$ ? $\mathrm{q}=$ dyslexia

dyslexia (n.d.-b). In Merriam-Webster medical dictionary. Retrieved from https://www.merriam-webster.com/dictionary/dyslexia

dyslexia (n.d.-c). Retrieved from https://www.merriam-webster.com/ dictionary/dyslexia

dyslexia (2002). Adopted by the International Dyslexia Association Board of Directors, Nov. 12, 2002. Retrieved from https:// dyslexiaida.org/definition-of-dyslexia/

dyslexia (2018). In American Medical Association ICD-10-CM 2018: the complete official codebook. Retrieved from https://www.icd10data. com/ICD10CM/Codes/F01-F99/F80-F89/F81-/F81.0

Eicher, J. D., \& Gruen, J. R. (2013). Imaging-genetics in dyslexia: connecting risk genetic variants to brain neuroimaging and ultimately to reading impairments. Molecular Genetics and Metabolism, 110, 201-212. j.ymgme.2013.07.001.

English, H. B., \& English, A. C. (1958). A comprehensive dictionary of psychological terms. A guide to usage. New York, NY: David McKay.

Fisher, S. E., \& DeFries, J. C. (2002). Developmental dyslexia: genetic dissection of a complex cognitive trait. Nature Reviews Neuroscience, 3, 767-780 nrn936.

Flanagan, D. P., Fiorello, C., \& Ortiz, S. O. (2010). Enhancing practice through application of Cattell-Horn-Carroll theory and research: a "third method" approach to specific learning disability identification. Psychology in the Schools, 47, 739-760 pits.20501.

Flanagan, D. P., Ortiz, S. O., \& Alfonso, V. C. (2013). Essentials of crossbattery assessment (3rd ed.). In A. S. Kaufman \& N. L. Kaufman (Eds.), Essentials of psychological assessment series. Hoboken, NJ: John Wiley \& Sons.

Flanagan, D. P., Ortiz, S. O., Alfonso, V. C., \& Mascolo, J. (2006). The achievement test desk reference (ATDR) (2nd ed.): a guide to learning disability identification. Hoboken, NJ: Wiley.

Flesch, R. (1955). Why Johnny can't read. New York, NY: Harper \& Row.

Fletcher, J. M., Stuebing, K. K., Barth, A. E., Miciak, J., Francis, D. J., \& Denton, C. A. (2014). Agreement and coverage of indicators of response to intervention: a multi-method comparison and simulation. Topics in Language and Learning Disorders, 34, 74-89 TLD.0000000000000004.

Fletcher, J. M., Reid Lyon, G., Fuchs, L. S., \& Barnes, M. A. (2018). Learning disabilities: from identification to intervention (2nd ed.). New York, NY: The Guilford Press.

Gamse, B. C., Jacob, R. T., Horst, M., Bouley, B., \& Unlu, F. (2008). Reading first impact study final report (NCEE 2009-4038). Washington, DC: National Center for Education Evaluation and Regional Assistance, Institute of Education Sciences, U.S. Department of Education.

Goodman, K. S. (1981). Letter to the editors. Reading Research Quarterly, 16, 477-478 747414.

Gray, W. S. (1940). Reading and factors influencing reading efficiency. In W. S. Gray (Ed.), Reading in general education (pp. 18-44). Washington, DC: American Council on Education.

Grigorenko, E. L. (2005). A conservative meta-analysis of linkage and linkage-association studies of developmental dyslexia. Scientific Studies of Reading, 9, 285-316 s1532799xssr0903 6.

Guilford, J. P. (1959). Three faces of intellect. American Psychologist, 14, 469-470.

Guilford, J. P., \& Hoepfner, R. (1971). The analysis of intelligence. New York: McGraw-Hill.

Hale, J. B., \& Fiorello, C. A. (2004). School neuropsychology: a practitioner's handbook. New York: Guilford Press.

Hammill, D. D., Mather, N., Allen, E. A., \& Roberts, R. (2002). Using semantics, grammar, phonology, and rapid naming tasks to predict word identification. Journal of Learning Disabilities, 35, 121-136 002221940203500204.

Hammill, D. D., McGhee, R. L., \& Ehrler, D. J. (2018). Detroit tests of learning abilities (5th ed.). Austin, TX: PRO-ED.

Hammill, D. D., \& McNutt, G. (1981). The correlates of reading: the consensus of thirty years of correlational research. Austin, TX: PRO-ED.

Hammill, D. D., Pearson, N., Hresko, W. P., Hoover, J. J., \& Allen, E. A. (2019). Models for screening children aged 6 and 7 for reading problems. Manuscript in preparation.

Hammill, D. D., Wiederholt, J. L., \& Allen, E. A. (2014). Test of silent contextual reading fluency (2nd ed.). Austin, TX: PRO-ED.

Harrison, A. G., \& Holmes, A. (2012). Easier said than done: operationalizing the diagnosis of learning disability for use at the postsecondary level in Canada. Canadian Journal of School Psychology, 27, 12-34 0829573512437021.

Huey, E. B. (1908). The psychology and pedagogy of reading. Cambridge, MA: MIT Press.

Jacobson, C. (1998). Reading development and reading disability: analyses of eye-movements and word recognition. Unpublished doctoral thesis, University of Lund, Sweden.

Johnson, E. S., Jenkins, J. R., Petcher, Y., \& Catts, H. W. (2009). How can we improve the accuracy of screening instruments? Learning Disabilities Research \& Practice, 24, 174-185 j.15405826.2009.00291.

Kamhi, A. G., \& Catts, H. W. (1989). Reading disabilities: a developmental language perspective. Boston, MA: Allyn \& Bacon. 
Kavale, K. A., Spaulding, C. S., \& Beam, A. P. (2009). A time to define: making the specific learning disability definition prescribe specific learning disability. Learning Disability Quarterly, 32, 39-48 25474661.

Kelly, L. J., \& Vergason, G. A. (1978). Dictionary of special education and rehabilitation. Denver, CO: Love.

Kirk, S. A., \& Chalfant, J. C. (1984). Academic and developmental learning disabilities. Denver, CO: Love.

Kranzler, J. H., Floyd, R. G., Benson, N., Zaboski, B., \& Thibodeaux, L. (2016). Classification agreement analysis of cross-battery assessment in the identification of specific learning disabilities in children and youth. International Journal of School and Educational Psychology, 4, 124-136 21683603.2016.1155515.

Lonigan, C. J., Schatschneider, C., \& Westberg, L., with the National Reading Panel. (2009). Identification of children's skills and abilities linked to later outcomes in reading, writing, and spelling. In Eunice Kennedy Shriver National Institute of Child Health and Human Development, National Institutes of Health, \& Department of Housing and Human Services (Eds.), Developing early literacy: executive summary of the National Early Literacy Panel (NA). Washington, DC: U.S. Government Printing Office.

Mather, N., Hammill, D. D., Allen, E. A., \& Roberts, R. R. (2014). Test of silent word reading fluency (2nd ed.). Austin, TX: PRO-ED.

Mather, N., \& Roberts, R. R. (1994). Learning disabilities: a field in danger of extinction? Learning Disabilities Research and Practice, 9, 49-58.

Meeker, M., Meeker, R., \& Roid, G. H. (1985). Structure of intellect learning abilities test-1985 edition. Torrance, CA: Western Psychological Services.

Miller-Guron, L. (1996). Wordchains: a matched English version of the Swedish Wordchains test. University of Goteborg, Sweden: Unpublished test.

Naglieri, J. A. (2010). The discrepancy-consistency approach to SLD identification using the PASS theory. In D. P. Flanagan \& V. C. Alfonso (Eds.), Essentials of specific learning disability identification (pp. 145-172). New York: Wiley.

National Institute of Child Health and Human Development. (2000). Report of the National Reading Panel. Teaching children to read: An evidence - based assessment of the scientific research literature on reading and its implications for reading instruction $(\mathrm{NIH}$ Publication No 00-4769 and 00-4754). washington, DC: U.S Government Printing Office.

Nelson, J. M. (2009). Psychometric properties of the Texas primary reading inventory for early reading screening in kindergarten. Assessment for Effective Intervention, 35, 45-53 1534508408326205.

Nicolosi, L., Harryman, E., \& Kreshech, J. (1989). Terminology of communication disorders, speech-language-hearing (3rd ed.). Baltimore, MD: Williams \& Wilkins. doi:00003446-19890400000015 .

Pearson Assessments. (1996). Stanford achievement test series, ninth edition technical data report. San Antonio, TX: Author.

Pasquale, J., Whitman, A., \& Whitman, B. A. (2002). Dictionary of developmental disabilities terminology (2nd ed.). Baltimore, MD: Paul H. Brooks.

Plomin, R., \& Kovas, Y. (2005). Generalist genes and learning disabilities. Psychological Bulletin, 131, 592-617 0033-2909.131.4.592.

Reid, D. K., Hresko, W. P., \& Hammill, D. D. (2018). Test of early reading ability (4th ed.). Austin, TX: PRO-ED.

Riedel, B. W. (2007). The relation between DIBELS, reading comprehension, and vocabulary in urban first-grade students. Reading Research Quarterly, 42, 546-567 RRQ.42.4.5.

Reynolds, C. R., \& Shaywitz, S. E. (2009). Response to intervention: ready or not? Or watch them fail. School Psychology Quarterly, $24,130-145$ a0016158.
Roid, G. H. (2003). Stanford-binet intelligence scales, fifth edition. Austin, TX: Pro-Ed, Inc.

Salvia, J., Ysseldyke, J. E., \& Witmer, S. (2017). Assessment in especial and inclussive education (13th ed.). Boston, MA: Cengage Learning.

Scarborough, H. S. (1998). Early identification of children at risk for reading disabilities. In B. K. Shapiro, P. J. Accardo, \& A. J. Capute (Eds.), Specific reading disability (pp. 75-119). Timonium, MD: York Press.

Scarborough, H. S. (2005). Developmental relationships between language and reading: reconciling a beautiful hypothesis with some ugly facts. In H. W. Catts \& A. G. Kamhi (Eds.), The connection between language and reading disabilities (pp. 3-24). Mahway, NJ: Erlbaum.

Shaywitz, S. E., \& Shaywitz, B. A. (2008). Paying attention to reading: the neurobiology of reading and dyslexia. Development and Psychopathology, 20, 1329-1349 S0954579408000631.

Shaywitz, S. E., Escobar, M. D., Shaywitz, B. A., Fletcher, J. M., \& Makuch, R. (1992). Evidence that dyslexia may represent the lower tail of a normal distribution of reading ability. New England Journal of Medicine, 326, 145-150 NEJM199201163260301.

Stanovich, K. E. (1988). Explaining the differences between the dyslexic and the garden-variety poor reader: the phonological-core variabledifference model. Journal of Learning Disabilities, 21, 590-604 002221948802101003.

Swanson, H. L. (1991). Operational definitions and learning disabilities: an overview. Learning Disability Quarterly, 14, 242-254 1510661.

Swanson, H. L., Trainin, G., Necoechea, D. M., \& Hammill, D. D. (2003). Rapid naming, phonological awareness, and reading. A meta-analysis of the correlational evidence. Review of Educational Research, 73, 407-44400346543073004407.

Thomson, M. (1984). Developmental dyslexia. Studies in disorders of communication (2nd ed.). London: Cole \& Whurr.

Torgesen, J. K., Wagner, R. K., \& Rashotte, C. A. (1999). Test of word reading efficiency. Austin, TX: PRO-ED.

Torgesen, J. K., Wagner, R. K., \& Rashotte, C. A. (2012). Test of word reading efficiency (2nd ed.). Austin, TX: PRO-ED.

Waesche, J. B., Schatschneider, C., Maner, J. K., Ahmed, Y., \& Wagner, R. K. (2011). Examining agreement and longitudinal stability among traditional and RTI-based definitions of reading disability using the affected-status agreement statistic. Journal of Learning Disabilities, 44, 296-307. https://doi.org/10.1177/ 0022219410392048.

Wagner, R. K. (2018). Why is it so hard to diagnose dyslexia and how can we do better? Retrieved from https://dyslexiaida.org/why-is-it-sodifficult-to-diagnose-dyslexia-and-how-can-we-do-it-better

Wagner, R. K., Torgesen, J. K., Rashotte, C. A., \& Pearson, N. A. (2010). Test of silent reading efficiency and comprehension. Austin, TX: PRO-ED.

Wiederholt, J. L., \& Bryant, B. R. (2012). Gray oral reading tests (5th ed.). Austin, TX: PRO-ED.

Wilson, S. B., \& Lonigan, C. J. (2010). Identifying preschool children at risk of later reading difficulties. Journal of Learning Disabilities, 42, 62-76 0022219409345007.

Wolman, B. B. (1989). Dictionary of behavioral science (2nd ed.). New York, NY: Academic Press.

World Federation of Neurology. (1968). Definition of dyslexia. Dallas, TX: Author

Youman, M., \& Mather, N. (2018). Dyslexia laws in the USA: a 2018 update. Perspectives on Language and Literacy, 44, 37-41.

Publisher's Note Springer Nature remains neutral with regard to jurisdictional claims in published maps and institutional affiliations. 